\title{
The Geschwind-Behan-Galaburda model (GBGM) of cerebral lateralization: a critique and prospective
}

\author{
C.M.J. Braun \\ Laboratoire de Neuroscience de la Cognition, and Département de Psychologie, \\ Université du Québec à Montréal, Canada
}

Correspondence to: C.M.J. Braun, LNC-UQAM, C.P. 8888, Succ. Centre-Ville, Montréal, Québec, Canada H3C 3P8

\begin{abstract}
In the wake of, and as a complement to, a recently published major meta-analytic review of empirical support of the Geschwind-Behan-Galaburda model (GBGM) of cerebral lateralization (CL) the present brief essay attempts to present a critical assessment of the theoretical approach underlying the GBGM. The GBGM is criticized for having been misguided in its representation of the cerebral basis of handedness, and of the links between testosterone and immune function. Some guidelines are presented for the development of a general theory of CL, emphasizing animal research, greater interdisciplinary communication, a hierarchical model-building approach, and the relevance of neuropharmacology and psychiatry.
\end{abstract}

Keywords: Cerebral laterality - Endocrine - Handedness - Immune - Neurotransmitter - Geschwind-Behan-Galaburda model

\section{INTRODUCTION}

The Geschwind-Behan-Galaburda model (GBGM) of cerebral lateralization (Geschwind and Galaburda, 1985 ) is a far reaching theory of the effects of prenatal testosterone on the development of hemispheric specialization with thymic immunity acting as a mediator. The GBGM continues to inspire behavioural neurology. Evidence to that effect is the special issue in Brain and Cognition (Bryden et al., 1994) which was entirely devoted to critical assessment of empirical evidence in support of the GBGM. That major review article, as well as the numerous commentaries, essentially led to the conclusion that there is virtually no support at all for the theory, at least as far as its claims regarding the development of hand dominance. The scientific community is coming to this conclusion after publication of several hundreds of research projects designed to test components of the theory, and yet seems to want to continue testing the model. It is the contention of the present essay that it is time to pass on to another paradigm of cerebral laterality, with an entirely different theoretical approach to the problem.
A first major problem with the GBGM was its heavy reliance on expeditive assessment of human handedness in a general model of cerebral lateralization (CL). As Bryden and colleagues have explained (1994), the biopsychosocial complexity of human handedness has been sorely underestimated. The problem with human handedness, as an index of $\mathrm{CL}$, is that it is a bad measure when extracted summarily. The ease with which it can be documented is, however, precisely the reason why it has been so popular. However, this catch-22 situation has corrupted our understanding of the cerebral aspects of handedness.

Secondly, it seems disappointing, in hindsight, that the clinically based associations forming the centroid of the GBGM were drawn piecemeal, the authors not having bothered to survey, for example, sex and age curbs of all the autoimmune, allergic and infectious diseases systematically. If such had been done, using the biomolecular data available at the time, the GBGM would never have been born. For example, the GBGM would not have attributed such importance, as it did wrongly, to thymic mediation of 
brain-immune developmental interactions (St Marseille and Braun, 1995).

Thirdly, more attention to animal research in neuroendocrinology and neuroimmunology would have helped inhibit some of the sweeping generalizations of the GBGM. For example, the effects of fetal androgens on CL could not plausibly have been reduced to slowing development of the left hemisphere. I elaborate on this in a later section. Furthermore, there was never any basis for reducing the GBGM selection of immune disorders to thymic atrophy in boys, and even less the latter to left handedness. On the other hand, normal development of the immune system does relate to $\mathrm{CL}$ in sexdimorphic manner in non-human species (Tobet and Fox, 1989). This is certainly a stronger basis for model building than speculation about associational clusters of immune disorders and non-immune marginalities.

How might we now re-build a general model of CL? Contrary to the GBGM, a general model or theory of CL must: (1) be based on animal research as well as human research; (2) draw the relevant material from each scientific discipline systematically and exhaustively prior to interdisciplinary integration; (3) propose theoretical models hinging not on the weakest associational clusters first but on the stronger ones; and (4) cover all the relevant scientific disciplines including neuropsychiatry and neuropharmacology. These four points will now be argued in more detail with a few examples.

\section{ANIMAL RESEARCH}

There are many hundreds of specific findings of CL in animal research obviously forming a complex mosaic. One of the more developed programs of research, in this general domain, is the work of Glick and colleagues on the neurodynamics of asymmetric turning behaviour in rats. The behavioural, genetic, neuropharmacokinetic, neuroendocrinological, neuroanatomical, and developmental aspects of this paradigm are now amazingly advanced (Zimmerberg 1974; Glick and Shapiro, 1985; Shapiro et al. 1986; Glick et al., 1988). This behaviour is clearly lateralized in its bodily expression as well as in its brain substrate and there is good fit between the two. The phenomenon is also sexually dimorphic, inherited, dopamine-mediated, and striatum-based. The paradigm has even been extended to the human (Bracha et al., 1987) and, therefore, an extremely interesting candidate as a prototype for continued deepening of our bioscientific understanding of CL.

Human handedness, like animal pawedness, is not only testosterone-dependent. In fact, testosterone explains only a very small portion (barely significant) of the variance. Genetic factors are obviously tremendously important. Human research has not, however, been able to show, and probably cannot show, the specific impact of asymmetric experience with the hands on cerebral anatomical or neurochemical asymmetry. Fortunately, the issue can be addressed in animal research. Diaz et al. (1994) trained very young rats to reach for food with only one paw. They later analyzed adult brains of rats with such precocious forced right or left pawedness, and adult brains with right and left spontaneous (untrained) right or left paw preference. Rats with precocious forced pawedness had greater development of the primary motor cortex of the hemisphere contralateral to the trained paw. The paw area of the motor strip was thicker and contained fewer neuron cell bodies, suggesting greater synaptogenesis. No such hemispheric asymmetry was observed in the rats with spontaneous paw preference.

Another highly relevant animal research paradigm introduced by Renoux et al. (1983) consists of investigating lateralization of hemispheric control of the immune system. Though there have been some controversial findings (Barnéoud et al., 1987; La Hoste et al., 1989; Belluardo et al. 1990), numerous independent studies have now reported that lateralized cortical lesions have opposite effects on proliferation and response of various lymphocyte types, including types that are not thymodependent. This animal paradigm has developed very rapidly and now incorporates data relating it to mouse paw preference and gender (Neveu et al., 1988) and to neuropharmacological asymmetries (Barnéoud et al., 1988; La Hoste et al., 1989). Four studies have recently begun to show that this CL also exists in humans (Lisianyi et al., 1989; Khil'ko et al., 1990; Kawaharada and Urasawa, 1992; St Marseille et al., 1996). Geschwind and his colleagues were justifiably interested in prenatal steroid influence on brain development. However, virtually nothing was, or is yet, known directly about this in humans. The direct evidence can only, and therefore must, be obtained from animal research. Otherwise, the wildest of speculations will continue to emerge, unchecked, and intriguing marginalities will be given excessive status in the overall scientific research agenda.

\section{ANALYSIS OF AVAILABLE DATA}

The GBGM proposed a broad link between left handedness and immune disorders, via foetal testosterone 
and atrophy of the thymus. This is a domain which exemplifies the importance of systematic and exhaustive analysis of available data prior to theorization. For example, there are numerous reports of menstrual, of gestational and of contraceptive modulation of immune and autoimmune activity, normal and pathological (Shoenfeld and Isenberg, 1989). Even more alarmingly for the GBGM, such male-prevalent traits as stuttering and high spatial ability are modulated by the menstrual cycle, in a manner specifically suggesting an estrogen factor (Silverman et al., 1974; Nyborg, 1983, 1984; Hampson, 1990), and there are numerous other examples of modulation by estrogen of functions postulated to be cerebrally lateralized. Finally, even prenatally, male and female mammalian brains in areas such as the cortex and the corpus callosum differ not only in brain-testosterone but also in brain-estrogen dynamics (Sandhu et al., 1986; Fitch et al., 1991).

The GBGM made broad statements to the effect that testosterone slows left hemisphere development. Careful analysis of the literature available now (and some available then) suggests, across a wide range of developmental brain dynamics and species, including humans, that all three sex steroid classes (especially testosterone, but occasionally also estrogen and progesterone) have a facilitatory rather than inhibitory effect on brain development. Examples apply to neuronal proliferation (Wright and Smolen, 1983), neurotransmitter metabolism (Goudsmit et al., 1990), neuronal migration (Kolata, 1979), myelination (Juraska and Kopcik, 1988), dendritic arborization and synaptogenesis (Menzies et al., 1982; Ayoub et al., 1983; Wright and Smolen, 1983), and resistance to neuronal mortality (Nordeen et al., 1985; Swaab and Hoffman, 1988). The few relevant empirical results obtained in humans so far are in mixed directions. For example, umbilical cord androgens are significantly negatively related to spatial ability of the offspring at age 6 years, but only in girls (Jacklin et al., 1988). This suggests the presence: of critical steroidsteroid interactions in fetal brain development precluding exclusive focus on any one steroid in any general model of CL. Consequently, it appears obvious that isolation of fetal testosterone and neglect of female steroids in modulation of CL is theoretically counterproductive.

\section{THEORETICAL MODELS BASED ON STRONG ASSOCIATIONS}

Aside from left hemisphere dominance for language, behavioral aspects of human CL are very subtle and controversial. The solution then is not to focus on the more evanescent behavioral manifestations of $\mathrm{CL}$, but rather on strong systemic (biological) associations which involve CL. For example, gender is obviously strongly involved in modulating immunity, but only weakly in CL. Female mammals clearly and consistently have stronger immune systems than males, except for IgE lymphocytes (Eidinger and Garrett, 1972), suffer less, and die less, from infections (Haber et al., 1982; Messadié, 1993), and suffer much more from autoimmune diseases (i.e. overactive immune responses). One gets a clearer picture of this when one reviews sex-prevalences in autoimmune diseases, most of which are not covered by the GBGM. Furthermore, males (especially prepubertal) have much higher rates of allergic disease involving $\operatorname{IgE}$ overactivity (Marsh et al., 1981). Starting from there, one is in a better position to blend in pieces of data relating the above to CL. Firstly, not all immune sex differences are thymodependent. Secondly, there is good reason to believe that sex steroids and certain neurotransmitters are integrated into asymmetric sex-dimorphic immunomodulatory brain systems, the prime chemical vectors possibly being serotonin (Ameison et al., 1989; Farber and Beer, 1991; Kelly, 1991; Dinarello, 1993), and to a lesser extent, noradrenaline (Madden and Livnat, 1991; Roszmann and Carlson, 1991). It seems to be often thought that human cerebral functional symmetry of language is a unique exemplar of radical hemispheric functional asymmetry, a perverse effect of anthropocentrism. Singing is just as radically and universally left hemisphere-lateralized in several bird species as language is in the human (Nottebohm, 1989). Furthermore, scientific understanding of the underlying neural mechanisms (neurochemical, neuroanatomical, endocrinological, genetic, environmental, developmental) is far more advanced for birdsong than it is for human speech (or handedness). Of course, this is not to suggest that the investigation of birdsong can in any way replace investigation of cerebral specialization for speech, only that general theories of cerebral laterality must take into account animal research.

\section{NEUROPSYCHIATRY AND NEUROPHARMACOLOGY}

\section{Neuropsychiatry}

Another example of a strong relation involving a weak link with CL is the sex-prevalence bias for certain neuropsychiatric diseases. For example, anorexia nervosa and psychopathy are strongly female and male biased respectively (each by approximately nine 
to one). Other common neuropsychiatric diseases, also very much sex-biased, include depression which is female preponderant and is clearly modulated by sex steroids (Meyer-Bahlburg and Ehrhardt, 1986) and hyperactivity and Gilles de la Tourette syndrome which are male preponderant. These syndromes are all the more relevant considering that they are all highly heritable and autosomal. The male-preponderant syndromes are virtually all manifest prepubertally and involve low anxiety and high turbulence. The female-preponderant syndromes are virtually all postpubertal and are stress-related and involve much anxiety. Even neuropsychiatric diseases which are not differentially prevalent as a function of sex over the full life-cycle tend to show the early onset bias for males and the late onset bias for females. These include schizophrenia (Seeman, 1982), motor disorders of the basal ganglia (Yassa et al., 1989), and the obsessive-compulsive syndrome (Flor-Henry, 1990). All three of these syndrome profiles support a hypothesis of an oestrogen protection factor against diseases involving dopamine overactivity (see Haefner et al., 1981; DiPaolo et al., 1985).

From there, one is in a solid position to explore meaningful hypotheses about $\mathrm{CL}$, such as various sorts of sexually dimorphic hormonally mediated asymmetric hemispheric fragilities including pharmacological hemispheric imbalances. For example, there is overwhelming evidence that serotonin-mediated brain mechanisms are more fragile in female than male mammals including humans (Goodwin et al., 1987; Anderson et al., 1990; Haleem et al., 1990).

\section{Neuropharmacology}

Having touched upon the importance of neuropsychiatry, let us insist on that of neuropharmacology. The GBGM makes little mention of neurochemical asymmetry. This is one domain where progress has been phenomenal in recent years. Several dozen chemical hemispheric asymmetries involving several neurotransmitters, and applying always to a subregion of the hemisphere (rarely to the entire hemisphere in non-human species), have been reported to apply to samples of animals of various species in a wide variety of cortical and sub-cortical areas, sometimes crossing over from one area to another. Some of these effects have been shown to interact with gender (Ross et al., 1981; Robinson et al., 1985; Drew et al., 1986; Lipsey and Robinson, 1986). Furthermore, oestrogen receptors are asymmetrically distributed in rat cortex, and the asymmetry is crossed as a function of sex (Sandhu et al., 1986). Androgen receptors are also distributed asymmetrically in male rhesus monkeys but not in the females (Scholl and Kim, 1990). These neuroendocrinological phenomena may be part of the basis for sex differences in neurotransmitter asymmetries. Hemispheric chemical asymmetries and sex differences in whole-brain neurochemical activity have also been found in the human. Such effects seem to involve acetylcholine (Amaducci et al., 1981), GABA (Post and Goodwin, 1975; Rossor et al., 1980), noradrenalin (Oke, 1978; Reynolds, 1983; Biegon, 1991), serotonin (Post and Goodwin, 1975; Reynolds and Czudek, 1987; Demeter et al., 1989; Frecska et al., 1990; Arato and Frecska, 1991), and dopamine (Post and Goodwin, 1975; Reynolds, 1983). [See also Glick et al. (1982).] The only sex-dimorphic neurotransmitter asymmetry we are aware of involves serotonin (Frecska et al, 1990; Arato and Frecska, 1991). Common sense dictates that such phenomena are much more likely than anatomical asymmetries or handedness (i.e. the GBGM) to be involved in immune system modulation or neuropsychiatric syndromes. Anatomical asymmetries can only be linked to behavioural asymmetries (c.f. GBGM) by analogy. What we need to determine is the chain of causation, or in other words, the sequence of mechanisms.

\section{CONCLUSION}

In light of all of which precedes, it seems to me that one research program which should retain our attention in view of building an integrative theory of $\mathrm{CL}$, is the following experimental animal research agenda: we need to determine the effects of targeted steroid manipulations on relevant neurotransmitter activity (see DiPaolo et al., 1981; Heritage et al., 1981, for examples) and vice versa (see Dorner et al., 1987; Dorner, 1988, for examples) as a function of precise intra- and interhemispheric loci in a developmental (especially prenatal) context. The timing, as well as intensities and durations of these manipulations will have to be very carefully controlled because acute and chronic, and low and high dose developmental manipulations often have opposite effects (see Biegon and McEwen, 1982; Haefner et al. 1991). Furthermore, steroid-steroid developmental brain dynamics (Diamond et al., 1973; Maclusky and McEwen, 1978; McEwen, 1981) will have to be taken into account as well as neurotransmitter-neurotransmitter dynamics (see Tucker and Williamson, 1984; Stanley et al., 1985), some being agonistic and others antagonistic. It would be fastidious and futile to do this independently of a well-structured behavioural paradigm. Though right and left paw preference are equally distributed in non-human mammals, paw preference is probably 
more akin to human hand preference than has been hitherto recognized (Bianki, 1988). In any event, the animal model presents certain basic advantages over the human model: paw preference is less affected by brain disorders (i.e. pathological left handedness), by cultural pressures, by biases due to learning and practice, and arbitrariness of measurement parameters than is human hand preference. Ironically, this brings us back to our starting point, namely handedness and the brain, but this time perhaps on more solid footing. One thing is for sure, never again will a general model of CL be presentable as a matter of whole hemispheres, of a single sex steroid, or of a single immune organ.

\section{Acknowledgement}

This essay is dedicated to the fond memory of Professor Philip Bryden whose untimely death deprives us of a great scientific investigator of cerebral laterality.

\section{REFERENCES}

Amaducci L, Sorbi S, Albanese A and Gainotti G (1981) Choline acetyl transferase (Chat) activity differs in right and left human temporal lobes. Neurology, 31, 799-805.

Ameison JC Meade R and Askenase PW (1989) A new interpretation of the involvement of serotonin delayedtype hypersensitivity. Journal of Immunology, 142, 3171-3176.

Anderson IM, Parry-Billings M, Newsholm EA, Fairburn CG and Cowen PJ (1990) Dieting reduces plasma tryptophan and alters brain 5-HT function in women. Psychological Medicine, 20, 795-791.

Arato M and Frecska E (1991) Serotonergic interhemispheric asymmetry: neurochemical and pharmaco-EEG evidence. Progress in Neuro-Psychopharmacology and Biological Psychiatry, 15, 759-764.

Ayoub DM, Greenough WT and Juraska UJ (1983) Sex differences in dendritic structure in the preoptic area of the juvenile macaque monkey brain. Science, 219, 197-198.

Barneoud P, Neveu PJ, Vitiello S and LeMoal M (1987) Functional heterogeneity of the right and left cerebral neocortex in the modulation of the immune system. Physiology and Behaviour, 41, 525-530.

Barneoud P, Rivet JM, Vitiello S, LeMoal M and Neveu PJ (1988) Brain norepinephrine levels after BCG stimulation of the immune system. Immunology Letters, 18, 201-204.

Belluardo N, Mudo G, Cella S and Bindoni M (1990) Effects of cerebral hemisphere decortication on the cytotoxic activity of natural killer and natural cytotoxic lymphocytes in the mouse. Brain Research, 524, 297-302.

Bianki UL (1988) The Right and Left Hemispheres of the Animal Brain. Gordon and Breach, New York.
Biegon A (1991) Acetylocholine serotonin, and B-adrenoceptors. In: Receptors in the Human Nervous System (Eds FAO Mendelsohn and G Paxinos) p 64. Academic Press, New York.

Biegon A and McEwen BS (1982) Modulation by oestradiol of serotonin receptors in brain. Journal of Neuroscience, 2, 199-205.

Brach HS, Seitz DJ, Otemaa J and Glick SD (1987) Rotational movement in normal humans. Sex difference and relationship to hand, foot and eye preference. Brain Research, 411, 231-235.

Bryden MP, McManus IC and Bulman-Fleming MB (1994) Evaluating the empirical support for the Geschwind-Behan-Galaburda Model of cerebral lateralization. Brain and Cognition, 26, 103-167.

Demeter E, Tekes K and Majorossy K (1989) The asymmetry of ${ }^{3} \mathrm{H}$-imipramine binding may predict psychiatric illness. Life science, 44, 1403-1410.

Diamond M, Llacuna A and Wong (1973) Sex behaviour after neonatal progesterone, testosterone, oestrogen or antiandrogens. Hormones and Behaviour, 4, 73-88.

Diaz E, Pinto-Hamuy $\mathrm{T}$ and Fernandez V (1994) Interhemispheric structural asymmetry induced by a lateralized reaching task in the rat motor cortex. European Journal of Neuroscience, 6. 1235-1238.

Dinarello CA (1993) Interleukin-1 and tumour necrosis factor. In: Clinical Aspects of Immunology (5th Edn) (Eds PJ Lachmann, K Peters, FS Rosen and MJ Walport), pp. 267-286). Blackwell Scientific Publications, Barton.

DiPaolo T, Payet P and Labrie F (1981) Effect of chronic oestradiol and haloperidol treatment on striatal dopamine receptors. European Journal of Pharmacology, 73, 105-106.

DiPaolo T, Rouillard C and Bédard P (1985) 17-Betaoestradiol at a physiological dose acutely increases dopamine turnover in rat brain. European Journal of Pharmacology, 117, 197-203.

Dorner G (1988) Neuroendocrine response to oestrogen and brain differentiation in heterosexuals, homosexuals and transsexuals. Archives of Sexual Behaviour, 17, $57-75$.

Dorner G, Dacke F, Rahde W, Stahl F and Tonjes R (1987) Sexual differentiation of gonadatrophin secretion sexual orientation and gender role behaviour. Journal of Steroid Biochemistry, 27, 1081-1087.

Drew KL, Lyon RA, Titelier M and Glick SD (1986) Asymmetry in D-2 binding in female rat striata. Brain Research, 363, 192-195.

Eidinger D and Garret TJ (1972) Studies of the regulatory effects of the sex hormones on antibody formation and stem cell differentiation. Journal of Experimental Medicine, 136, 1098-1116.

Farber AW and Beer DJ (1991) Restricted secretion of a Tlymphocyte chemotactic cytosine by serotonin-stimulated cultured aortic endothelial cells. Circulation Research, 69, 257-265.

Fitch HR, Cowell PE, Schrott LM and Denenberg VH (1991) Corpus callosum: ovarian hormone and feminization. Brain Research, 542, 313-317.

Flor-Henry P (199) Le syndrome obsessional-compulsif: reflet d'un défaut de régulation fronto-caudée de l'hemisphère gauche? Encéphale, 16, 325-329. 
Frecska E, Arato M, Tekes K and Powchik P (1990) Lateralization of $3 \mathrm{H}-\mathrm{IMI}$ binding in human frontal cortex. Biological Psychiatry, 27, 72A.

Geschwind N and Galaburda AM (1985) Cerebral lateralization. Biological mechanisms, association and pathology I, II and III: a hypothesis and a program for research. Archives of Neurology, 42, 521-552.

Glick SP and Shapiro RM (1985) Functional and neurochemical mechanisms of cerebral lateralization in rats. In: Cerebral lateralization in non-human species (Ed. SP Glick), Academic Books, New York.

Glick SP, Ross DA and Hough LB (1982) Lateral asymmetry of neurotransmitters in human brain. Brain Research, 234, 53-63.

Glick SD, Lyon RA, Hinds PA, Sowek C and Titeler M (1988) Correlated asymmetries in striatal D1 and D2 binding: relationship to apomorphine-induced rotation. Brain Research, 455, 43-48.

Goodwin GM, Fairburn CF and Cowen PJ (1987) Dieting changes serotonergic function in women not men: implication for the aetiology of anorexia nervosa? Psychological Medicine, 17, 839-842.

Goudsmit E, Feenstra MGP and Swaab DF (1990) Central monoamine metabolism in the male brown-norway rat in relation to aging and testosterone. Brain Research Bulletin, 25, 755-764.

Haber SA, Job LP and Auld KR (1982) Influence of sex hormones on loxsackie B-3 virus infection in BALB/c mice. Cellular Immunology, 67, 173-179.

Haefner H, Behrens S, De-Ury J and Gathaz WF (1991) An animal model for the effects of oestradiol on dopaminemediated behaviour. Implications for sex differences in schizophrenia. Psychiatry Research, 38, 125-134.

Haleem DJ, Kennett GA and Curzon G (1990) Hippocampal 5-hydroxytryptamine synthesis is greater in female rats than in males and more decreased by the 5-HT agonist 8-OH-DPAT. Journal of Neural Transmission, 79, 93-101.

Hampson E (1990) Oestrogen-related variations in human spatial and articulatory-motor skills. Psychoneuroendocrinology, 15, 97-111.

Heritage AS, Stumpf WE, Sar M and Grant LD (1981) ${ }^{3} \mathrm{H}-$ dihydrotestosterone in catecholamine neurons of rat brain stem: combined localisation by autoradiography and formaldehyde-induced fluorescence. Journal of Comparative Neurology, 200, 289-307.

Jacklin CN, Wilcox KT and Maccoby EE (1988) Neonatal sex-steroid hormones and cognitive abilities at six years. Developmental Psychobiology, 21, 567-574.

Juraska JM and Kopcik JR (1988) Sex and environmental influences on the size and ultrastructure of the rat corpus callosum. Brain Research, 450, 1-8.

Kawaharada M and Urasawa K (1992) [Immunological functions and clinical course of elderly patients with cerebrovascular diseases]. Nippon Ronen Tgakkai Zasshi, 29, 652-660. (Japanese).

Kelly DD (1991) Sleep and dreaming. In: Principles of Neural Science (3rd edn) (Eds, ER Kandel JH Schwartz and TM Jessell) (pp. 805-819). Appleton and Lange, Norway.

Khil'ko VA, Usanov EI, Khlunovoskii AN and Gizatullin CK (1991) [Relations between the phagocytic activity of monocytes and the lateralization of brain injuries]. Zhurnal Neuropathologie Psikhiatrii, 90, 16-20 (Russian).
Kolata GB (1979) Sex hormones and brain development. Science, 205, 985-987.

La Hoste GL, Neveue PJ, Mormède P and Le Moal M (1989) Hemispheric asymmetry in the effects of cerebral cortical ablations on mitogen-induced lymphoproliferation and plasma prolactin in female rats. Brain Research, 483, 123-129.

Lipsey JR and Robinson RG (1986) Sex dependent behavioural response to frontal cortical section lesions in the rat. Life Sciences, 38, 2185-2192.

Lisianyi NI, Markova OU, Prokhodtchenko IA and Primuschko LI (1989) [Humoral and cellular immunity in patients with left and right sided intracerebral tumour]. Zhurnal Voprosy Neurokhirurgie, 2, 33-35. (Russian).

Maclusky NJ and McEwen BS (1978) Oestrogen modulates progestin receptors concentrations in some rat brain regions but not in others. Nature, 274, 276-278.

Madden KS and Livnat S (1991) Catecholamine action and immunologic reactivity. In: Psychoneuroimmunology (2nd edn.) (Eds R Alder, DL Felten and N Cohen), (pp. 283-310). Academic Press, Toronto.

Marsh DG, Meyers DA and Bias WB (1981) The epidemiology and genetics of atopic allergy. New England Journal of Medicine, 305, 1551-1559.

McEwen BS (1981) Neural gonadal steroid actions. Science, 211, 1303-1311.

Menzies KD, Drysdale DB and Waite PME (1982) Effects of prenatal progesterone on the development of pyramidal cells in rat cerebral cortex. Experimental Neurology, 77, 654-667.

Messadié G (1993) L'homme est-il une femme ratée? Science and Vie, 904, 28-43.

Meyer-Bahlburg HFL and Ehrhardt AA (1986) Prenatal diethylstilboestrol exposure: behavioural consequences in humans. In: Systemic Hormones Neurotransmitters and Brain Development (Eds G Dorner SM McCaun and L Martini), Karger, Basel.

Neveu PJ, Barneoud P, Vitiello S, Bétancur C and Le Moal M (1988) Brain modulation of the immune system. Association between lymphocyte responsiveness and paw preference in mice. Brain Research, 457, 392-394.

Nordeen EJ, Nordeen KW, Sengelaub DK and Arnold AP (1985) Androgens prevent normally occurring cell death in a sexually dimorphic spinal nucleus. Science, 299, 671-673.

Nottebohm F (1989) Birdsong. In: Learning and Memory, (Ed. RF Thompson), Birhauser, Cambridge, MA.

Nyborg H (1983) Spatial ability in men and women: review and new theory. Advances in Behavioural Research and Therapy, 5, 89-140.

Nyborg H (1984) Performance and intelligence in hormonally difference groups. Progress in Brain Research, 61, 491-508.

Oke A, Keller H, Meffors I and Adams RN (1978) Lateralization of norepinephrine in human thalamus, Science 200, 1411-1413.

Post RM and Goodwin FK (1975) Studies of cerebrospinal fluid amine metabolites in depressed patients conceptual problems and theoretical implications. In: The Psychobiology of Depression (Ed. J Mandels), pp. 47-67. Spectrum, New York.

Renoux G, Bizere K, Renoux M, Guillaumin JM and Degenne D (1983) The production of T-cell-inducing 
factors in mice is controlled by brain neocortex. Scandinavian Journal of Immunology, 17, 45-50.

Reynolds GP (1983) Increased concentrations and lateral asymmetry of amygdal dopamine in schizophrenia. Nature, 305, 527-529.

Reynolds GP and Czudek C (1987) Neurochemical laterality of the limbic system in schizophrenia. In: Cerebral Dynamics Laterality and Psychopathology (Eds R Takahashi P Flor-Henry J Gruzelier and S Niwa), Elsevier, Amsterdam.

Robinson TE, Becker JB, Camp DM and Mansour A (1985) variation in the pattern of behavioural and brain asymmetries due to sex differences. In: Cerebral Lateralization in Nonhuman Species (Ed. AS. Glick), Academic Books, New York.

Ross DA, Glick SD and Meibach RC (1981) Sexually dimorphic brain and behavioural asymmetries in the neonatal rat. Proceedings of the National Academy of Sciences USA, 78, 1958-1961.

Rossor, M, Garrett N and Iversen L (1980) No evidence for lateral asymmetry of neurotransmitters in post-mortem human brain. Journal of Neurochemistry, 35, 743-745.

Roszman TL and Carlson SL (1991) Neurotransmitters and molecular signalling in the immune response. In: Psychoneuroimmunology, (2nd Edn.), (Eds R Ader DL Felten and N Cohen) (pp. 311-336). Academic Press, Toronto.

Sandhu S, Cook P and Diamond MC (1986) Rat cerebral cortical oestrogen receptors: male-female, right-left. Experimental Neurology, 92, 186-196.

Seeman MV (1982) Gender differences in schizophrenia. Canadian Journal of Psychiatry, 27, 107-112.

Shapiro RM, Glick SD and Hough LB (1986) Striatal dopamine uptake asymmetries and rotational behaviour in unlesioned rats: Revising the model? Psychopharmacology, 89, 25-30.

Shoenfeld Y and Isenberg D (1989) The mosaic of autoimmunity In: Research Monographs in Immunology (Vol. 12) Elsevier, Amsterdam.

Sholl SA and Kim KL (1990) Androgen receptors are differentially distributed between right and left cerebral hemispheres of the foetal male rhesus monkey. Brain Research, 516, 122-126.

Silverman EM, Zimmer CH and Silverman FH (1974) Variability of stutterer's speech disfluency: The menstrual cycle. Perceptual and Motor Skills, 38, 1037-1038.

Stanley M, Traskman-Bendz KL and Dorovini-Zis K (1985) Correlations between aminergic metabolites simultaneously obtained from human CSF and brain. Life Sciences, 37, 1279-1286.

St Marseille A and Braun CMJ (1994) Comments on immune aspects of the GBG model and on the article of Bryden, MacManus and Bulman-Flemming. Brain and Cognition, 26, 281-290.

St Marseille A, Kouassi G, D'Angelo P, Laplante S, Cheng ML, Trouvé F, Gilbert F, Geadah D and Braun CMJ (1996) Opposed left and right neocortical involvement in the immune response indexed by cerebrovascular accidents in humans: preliminary results. Brain and Cognition 32, 173-175

Swaab DF and Hofman MA (1988) Sexual differentiation of the human hypothalamus: autogeny of the human hypothalamus: autogeny of the sexually dimorphic nucleus of the preoptic area. Developmental Brain Research, 44, 314-318.

Tobet SA and Fox T (1989) Sex and hormone-dependent antigen immunoreactivity in developing rat hypothalamus. Proceedings of the National Academy of Sciences USA, 86, 382-386.

Tucker DM and Williamson PA (1984) Asymmetric neural control systems in human self-regulation. Psychological Review, 91, 185-215.

Wright LL and Smolen AJ (1983) Neonatal testosterone treatment increases neuron and synapse numbers in male rat superior cervical ganglion. Development Brain Research, 8, 145-153.

Yassa R, Nair V and Iskanda H (1989) A comparison of severe tardive dystonia and tardive dyskinesia. Acta Psychiatrica Scandinavica, 80, 155-159.

Zimmerberg B, Glick SD and Jerussi TP (1974) Neurochemical correlate of a spatial preference in rats. Science 185, 623-625. 


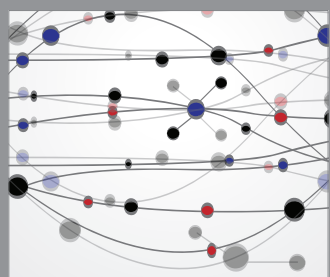

The Scientific World Journal
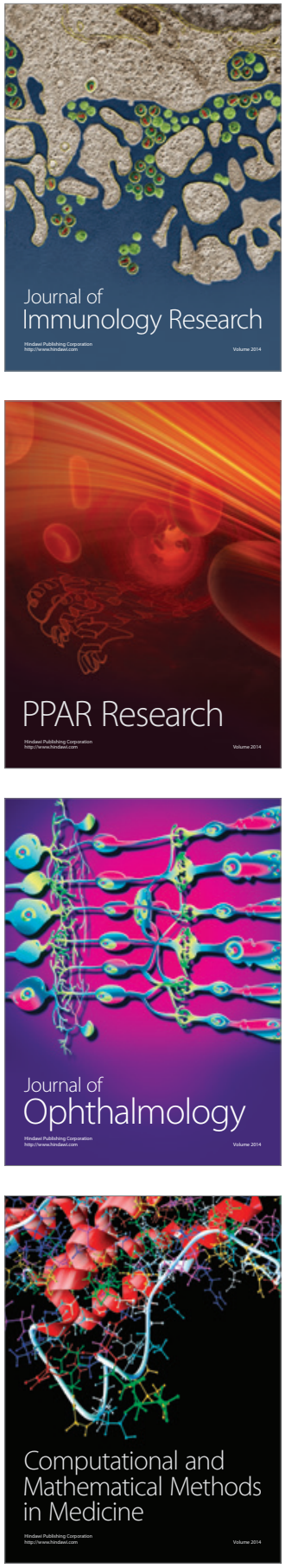

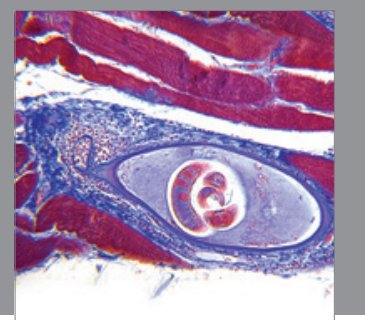

Gastroenterology

Research and Practice
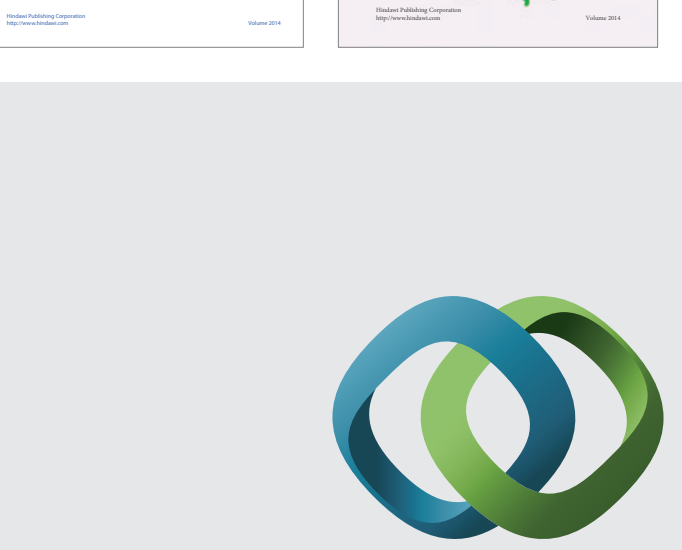

\section{Hindawi}

Submit your manuscripts at

http://www.hindawi.com
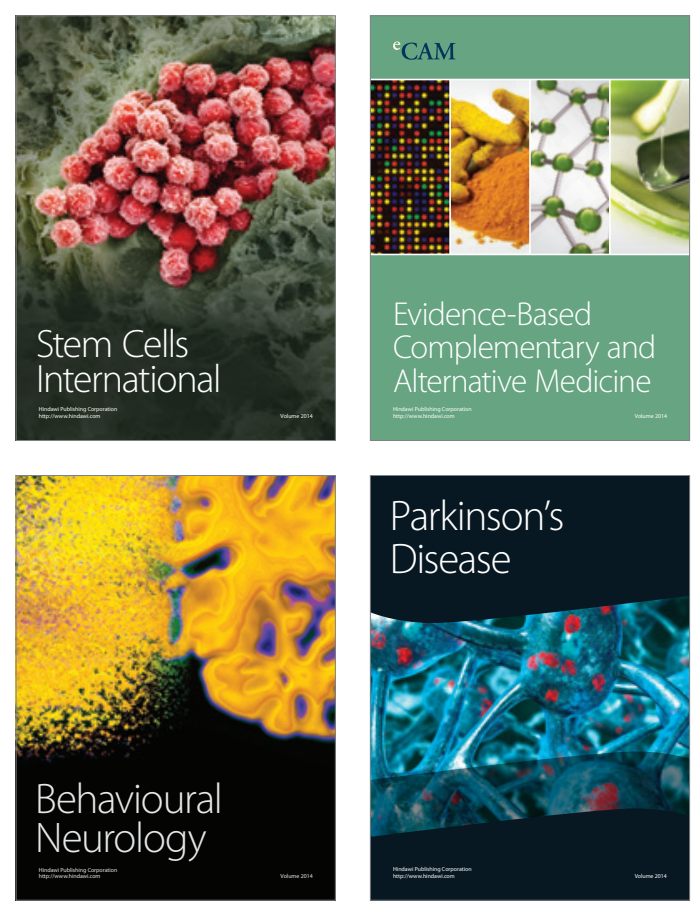

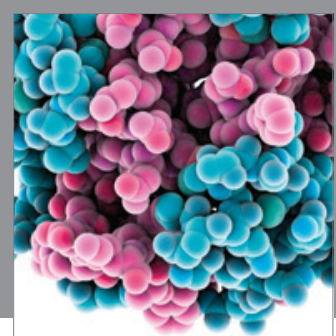

Journal of
Diabetes Research

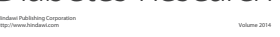

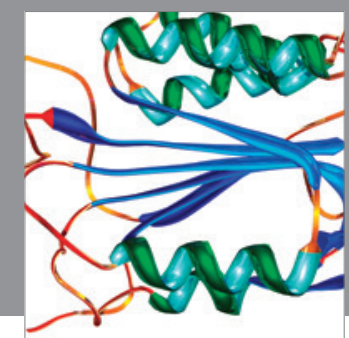

Disease Markers
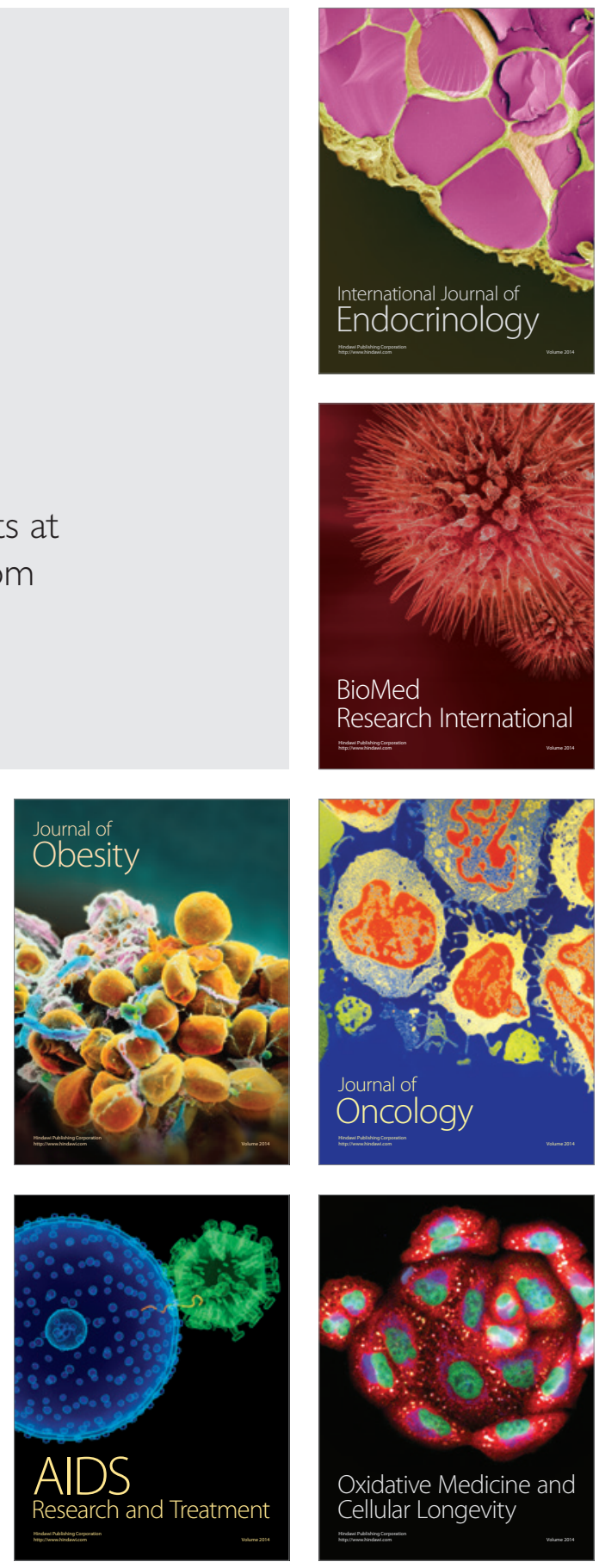